\title{
Co

\section{Sharing the responsibility for assessing the risk of the driver with dementia}

\author{
Mark J. Rapoport MD, Nathan Herrmann MD, Frank J. Molnar MDCM, Malcolm Man-Son-Hing MD, \\ Shawn C. Marshall MD MSc, Ken Shulman MD, Gary Naglie MD
}

W hen the physician's role of caring for patients collides with the duty of societal protection, a dramatic and controversial dynamic occurs that often strains the doctor-patient relationship. Nowhere is this more salient than in the case of a patient with mild dementia who the physician thinks may be an unsafe driver. In most Canadian provinces and all territories, physicians have a mandatory duty to report these patients to the relevant licensing authorities (Table I). In Alberta, Nova Scotia and Quebec, the duty to report is discretionary. In British Columbia, reporting is mandatory if an unsafe driver continues to drive despite being warned of the danger. ${ }^{1}$ However, none of these legislations directly address dementia. Internationally, even wider variation exists among legislations and recommendations about drivers with dementia. ${ }^{2-5}$

\section{The problem}

Driving is a privilege, and if a medical condition interferes, public safety is at risk. It is estimated that by 2028 , on Ontario roads there will be more than 98 ooo drivers with dementia, ${ }^{7}$ a condition that may put these drivers at a substantially increased risk for crashes ${ }^{8}$ From a national perspective, this means that we can reasonably expect that the number of active drivers with dementia will be in the hundreds of thousands. Although many drivers with progressive dementia may remain safe drivers in the early stages, all will become unsafe drivers in the later stages. ${ }^{9}$ Of all instrumental activities in daily life that are adversely affected by dementia, driving is potentially the deadliest. Physicians are usually the first health care providers to identify patients with dementia. However, physicians often do not feel confident in assessing their patients' medical fitness to drive, as standardized evidence-based guidelines are lacking. Furthermore, specialized on-road testing is not available in all locations, and where it is available, its substantial cost (several hundred dollars) is usually borne by the patient. From a social equity perspective, people with fewer financial resources cannot afford such expensive on-road testing and consequently may have to cease driving whether or not they are safe drivers.

The current situation often puts physicians in a manda-

\section{Key points of the article}

\section{Major concerns}

- There are a growing numbers of drivers with dementia

- Physicians often fail to recognize unsafe drivers with dementia

- There are no valid in-office tests available to predict individual driving risk

- On-road tests are often costly and unavailable

\section{Proposed solutions}

- Improved access to and subsidization of specialized on-road testing

- Increased support and transportation alternatives to help patients and caregivers cope with driving cessation

- Research into and development of tools for office-based driving assessment

- Improved physician education about dementia recognition and driving assessment

tory policing role without the needed tools to accurately assess driving safety. Furthermore, when the physician complies with legislation to report potentially unsafe drivers, there is often acrimony and occasionally termination of the doctor-patient relationship. Not surprisingly, many physicians opt not to comply with their mandatory duty to report. A survey of 517 physicians in Saskatchewan indicated that that $27.3 \%$ of respondents hesitated to report medically unfit drivers and that $15.1 \%$ were noncommittal. ${ }^{10}$ The recognition of dementia in primary care settings is relatively low, ${ }^{11}$ and

From the Division of Clinical Integrative Biology (Rapoport, Shulman) and the Division of Geriatric Psychiatry (Herrmann), Sunnybrook Health Sciences Centre, Toronto; the Department of Psychiatry (Rapoport, Herrmann, Shulman), University of Toronto; the Division of Geriatric Medicine (Molnar, Man-Son-Hing), The Ottawa Hospital; the Department of Medicine (Molnar, Marshall, Man-Son-Hing), University of Ottawa; the Institute for Rehabilitation Research and Development (Marshall), the Department of Physical Medicine and Rehabilitation, Élizabeth Bruyère Health Centre, Ottawa; and the Division of Clinical Decision Making and Health Care (Naglie), Toronto Rehabilitation Institute, University Health Network, Toronto. Rapoport, Molnar, Man-Son-Hing, Marshall and Naglie are members of CanDRIVE (the Canadian Driving Research Initiative for Vehicular Safety in the Elderly). 
when patients or families approach their physician for help with cognitive symptoms, they do not expect their license to be revoked as a consequence. Thus, in addition to problems with recognition of dementia in primary care settings, the pressure to maintain the doctor-patient relationship, a lack of evidence-based guidelines and a lack of available and affordable on-road testing are likely key reasons for the failure to recognize unsafe drivers with dementia.

\section{Canadian guidelines}

The recent publication of the 7 th edition of the Canadian Medical Association's (CMA) Guide for Determining Medical Fitness to Operate Motor Vehicles states that moderate- to-severe dementia is a contraindication to driving and that a substantial proportion of patients with early-stage dementia are able to drive safely. ${ }^{1}$ A key suggestion in the guide is that the fitness to drive of patients with mild dementia should be tested on an individual basis. However, the guide acknowledges the limitation of using in-office tests, such as the Mini-Mental State Examination, for screening and quantifying cognitive impairment as a primary determinant of collision risk. Cognitive screening tools can be helpful in identifying patients with dementia; however, despite many efforts to date, no in-office cognitive screening tool or test battery has been demonstrated to accurately predict collisions among patients with dementia. ${ }^{12}$ The CMA guide advises a comprehensive off-

Table 1: Legislation on mandatory reporting of patients with dementia to licensing authorities and recommendations for assessing drivers with dementia

\begin{tabular}{|c|c|c|}
\hline Location & Mandatory reporting & Recommendations \\
\hline United States ${ }^{2,3}$ & $\begin{array}{l}\text { - California: disorders characterized by lapses of } \\
\text { consciousness (e.g., Alzheimer's disease and } \\
\text { related disorders) } \\
\text { - Pennsylvania: neuropsychiatric conditions (e.g., } \\
\text { Alzheimer's disease) } \\
\text { - Delaware, Nevada, New Jersey: conditions with } \\
\text { losses or lapses of consciousness (no specific } \\
\text { mention of dementia) } \\
\text { - Oregon: severe cognitive and functional } \\
\text { impairments } \\
\text { - Indiana: "handicapped persons" } \\
\text { - Arizona, Connecticut, Idaho, Kentucky, Maine, } \\
\text { New Mexico: “Yes, not specified" (the meaning of } \\
\text { this is unclear) } \\
\text { - Other states: no mandatory reporting }\end{array}$ & $\begin{array}{l}\text { Diagnosis of dementia is not sufficient to withdraw driving } \\
\text { privileges } \\
\text { - Withdrawal of driving privileges should be based on the } \\
\text { individual's driving ability } \\
\text { - Focused medical assessment with a formal assessment of } \\
\text { driving skills is required in cases where there is concern } \\
\text { about driving ability }\end{array}$ \\
\hline Australia ${ }^{4}$ & $\begin{array}{l}\text { - Required in the Northern Territory and South } \\
\text { Australia only } \\
\text { - People who are "physically or mentally incapable } \\
\text { of driving" (no specific mention of dementia) }\end{array}$ & $\begin{array}{l}\text { - Should not drive if memory, visuospatial skills, insight or } \\
\text { judgment are substantially impaired } \\
\text { - Emphasis is placed on the importance of a baseline and } \\
\text { periodic review of driving skills } \\
\text { - "If unsure, refer to a driver assessor" }\end{array}$ \\
\hline New Zealand ${ }^{5}$ & $\begin{array}{l}\text { Only if an individual is likely to drive despite } \\
\text { medical advice (no specific mention of dementia) }\end{array}$ & $\begin{array}{l}\text { - Should not drive if impaired cognition may affect driving } \\
\text { safety } \\
\text { - May be able to drive if the patient has early dementia with } \\
\text { intact insight and judgment and no disorientation or } \\
\text { confusion } \\
\text { - Cognitive assessment and specialist referral suggested } \\
\text { - "A full assessment of driving skills... will often be a } \\
\text { valuable way of determining whether an individual may } \\
\text { continue to drive a motor vehicle" }\end{array}$ \\
\hline $\begin{array}{l}\text { United } \\
\text { Kingdom }^{6}\end{array}$ & $\begin{array}{l}\text { - No mandatory reporting } \\
\text { - Physicians are advised to report patients who are } \\
\text { likely to continue driving despite being warned of } \\
\text { the risk }\end{array}$ & $\begin{array}{l}\text { - Patients with symptoms of impaired memory, } \\
\text { disorientation, lack of insight and judgment are "almost } \\
\text { certainly not fit to drive" } \\
\text { - "In early dementia, formal driving assessment may be } \\
\text { necessary" }\end{array}$ \\
\hline
\end{tabular}


road and on-road test at a specialized driving centre, and patients deemed fit to drive should be re-evaluated and possibly retested every 6 to 12 months.

In a cross-sectional study that included 50 patients with dementia, patients, patient informants and an experienced neurologist were asked to classify the patients' driving fitness as "safe" or "unsafe." ${ }^{13}$ For patients, the number of correct classifications (compared with an on-road assessment) was $53 \%$, compared with $64 \%$ for informants and $74 \%$ for the neurologist. Hence, even a highly experienced neurologist misclassified more than one-quarter of patients. The rate of misclassification would undoubtedly be higher for less experienced and nonspecialized physicians. Although no studies to date have established the sensitivity and specificity of on-road testing in relation to real-world collisions, on-road testing is currently recognized as the most objective method ("gold standard") to assess the driving ability of patients with mild dementia. At present, physicians can easily, and at no cost to patients, order laboratory tests and neuroimaging for patients with dementia, but the same cannot be said for comprehensive on-road driving assessments.

\section{Potential solutions}

Physicians should be responsible for diagnosing dementia and recognizing that this condition poses a safety risk for driving. The CMA guide can provide some direction for clinicians in their everyday practice, but there is a need for more education about recognizing dementia and assessing driving ability. Better office-based screening tools need to be developed to allow physicians to accurately classify drivers as safe or unsafe, so that only drivers in the "grey zone" will need more comprehensive and expensive testing.

Such borderline cases with mild dementia must be referred to specialized driving centres for comprehensive on-road testing, and it is our society's obligation to ensure that such testing is available in a timely and affordable manner. Provincial and territorial governments and automobile insurance companies should facilitate and subsidize testing for patients with mild dementia who are considered high risk. A useful analogy is the sequence of events that occurs if a physician reports a suspected case of child abuse to the Children's Aid Society. Physicians are not expected to perform the assessments of abuse themselves, nor are the suspected adults expected to pay for these assessments. Instead, government-sponsored independent experts are enlisted to perform individualized assessments. Although subsidized testing may be costly, this cost may prove to be relatively insignificant compared with the cost of crashes. In Ontario alone, the annual societal costs of motor vehicle collisions was estimated to be more than $\$ 9$ billion in $1990,{ }^{14}$ and this cost has likely escalated since.

The burden of driving cessation also needs to be addressed at the societal level. Resources such as subsidized transportation alternatives and social support services should be made increasingly available to help patients with dementia and their caregivers to cope with the mobility challenges and psychosocial consequences of driving cessation.

Although large-scale research is needed to prove that systematic individualized testing for drivers with dementia is effective and economical, creative and empiric solutions are needed now, given the large numbers of drivers with dementia on the roads. As the prevalence of dementia will continue to increase in years to come, there will be a greater demand for office-based tools for driving assessment and for specialized testing that can objectively assess and reassess the road safety of people with mild dementia.

\section{This article has been peer reviewed.}

Competing interests: None declared for Nathan Herrmann, Frank Molnar, Malcolm Man-Son Hing, Shawn Marshall, Ken Shulman and Gary Naglie. Mark Rapoport has received speaker fees from the Alzheimer's Society of St. Thomas, Janssen-Ortho and Novartis and has served on the advisory board of Janssen-Ortho.

Contributors: All of the authors made substantial contributions to the conception and design of the manuscript, drafted the article and revised it critically for important intellectual content. All of the authors approved the final version submitted for publication.

\section{REFERENCES}

I. Canadian Medical Association. Determining medical fitness to operate motor vehicles: CMA driver's guide. 7 th ed. Ottawa: The Association; 2006.

2. Wang CC, Kosinski CJ, Schwartzberg JG et al. Physician's guide to assessing and counseling older drivers. Washington: National Highway Traffic Safety Administration; 2003. Available: www.ama-assn.org/ama/pub/category/I079I.html (accessed 2007 Aug 7).

3. Oregon.gov. Oregon Department of Motor Vehicles. Available: www.oregon.gov /ODOT/DMV/atrisk/report.html (accessed 2007 Aug 9).

4. The National Transport Commission and Austroads. Assessing fitness to drive. Australia: The Commission; 2006. Available: www.austroads.com.au/aftd/index .html (accessed 2007 July 23).

5. Medical aspects of fitness to drive: a guide for medical practitioners. Available: www .landtransport.govt.nz/licensing/docs/ltsa-medical-aspects.pdf(accessed 2007 Aug 9).

6. Driver and Vehicle Licensing Agency. At a glance guide to the current medical standards of fitness to drive. United Kingdom: The Agency; 2007. Available: www.dvla.gov.uk/medical/ataglance.aspx?keywords=At+a+glance+guide+to+the+ current+medical+standards+of+fitness+to+drive (accessed 2007 July 23).

7. Hopkins RW, Kilik L, Day DJ, et al. Driving and dementia in Ontario: a quantitative assessment of the problem. Can J Psychiatry 2004;49:434-8.

8. Duchek JM, Carr DB, Hunt L, et al. Longitudinal driving performance in earlystage dementia of the Alzheimer type. J Am Geriatr Soc 2003;51:1342-7.

9. Friedland RP, Koss E, Kumar A, et al. Motor vehicle crashes in dementia of the Alzheimer type. Ann Neurol I988;24:782-6.

Io. Marshall SC, Gilbert N. Saskatchewan physicians' attitudes and knowledge regarding assessment of medical fitness to drive. CMAJ I999;160:I70I-4.

II. Borson S, Scanlan JM, Watanabe J, et al. Improving identification of cognitive impairment in primary care. Int J Geriatr Psychiatry 2006;21:349-55.

I2. Molnar FJ, Patel A, Marshall S, et al. Clinical utility of office-based cognitive predictors of fitness to drive in persons with dementia: a systematic review. J Am Geriatr Soc 2006;54:1809-24.

I3. Brown LB, Ott BR, Papandonatos GD, et al. Prediction of on-road driving performance in patients with early Alzheimer's disease. J Am Geriatr Soc 2005; 53:94-8.

I4. Vodden K, Meng R, Smith D, et al. The social cost of motor vehicle crashes, final report to Ontario Ministry of Transportation. Ottawa: Abt Associates of Canada; I994.

Correspondence to: Dr. Mark J. Rapoport, Department of Psychiatry, Sunnybrook Health Sciences Centre, Suite FG37, 2075 Bayview Ave., Toronto ON M4N 3M5; fax $4{ }_{1} 6$ 480-6o22; mark.rapoport@sunnybrook.ca 